\title{
Customer expectations of unattended grocery delivery services: mapping forms and determinants
}

Expectations of unattended grocery delivery

\author{
John Olsson, Mary Catherine Osman, Daniel Hellström and \\ Yulia Vakulenko \\ Department of Design Sciences, Packaging Logistics, Lund University, \\ Lund, Sweden
}

Received 23 July 2020

Revised 18 August 2020

9 February 2021

14 June 2021

15 June 2021

Accepted 10 August 2021

\begin{abstract}
Purpose - In the rapidly growing e-grocery segment, unattended delivery is an emerging practice with the potential to offer a superior delivery experience. The purpose of this study is to contribute to the body of knowledge for unattended grocery delivery services by empirically identifying and describing the forms and determinants of customer expectations.

Design/methodology/approach - A multiple case study of potential early adopters was conducted to explore customer expectations of unattended grocery delivery services. Empirical data collected from direct observations and semi-structured interviews with ten Swedish households were coded and put through a single-case as well as a cross-case analysis revealing emerging patterns from which propositions were formed. Findings - The iteration of theory and data in the case study resulted in a conceptual model of service expectations and determinants, containing six propositions. The study reveals a clear pattern that consumers expect to save time, gain flexibility and benefit from the ease of use of the service, while they predict sufficient security. Moreover, consumers' desire open access features from retailers and service providers, integrated product returns service and nondescript hardware designs. The findings suggest that these service expectations are determined by personal needs, technology literacy and situational factors. The identified personal needs are stress reduction, limiting social interaction and increasing spare time.

Research limitations/implications - To support further theory development, this study presents six propositions for the types, forms and determinants of customer expectations of unattended grocery delivery. Practical implications - This study provides managers with up-to-date insights into customer expectations and offers guidance in designing and developing unattended grocery delivery services.

Originality/value - This study contains the first in-depth analysis of customer expectations of unattended grocery delivery services, which are increasingly used for last mile e-grocery delivery.
\end{abstract}

Keywords Customer expectations, Unattended delivery, Last mile, Grocery, Retail, Service

Paper type Research paper

\section{Introduction}

While the e-commerce penetration rate of the grocery sector is still relatively low, e-grocery is nonetheless one of the fastest growing retail segments. The fresh food e-commerce market volume in China increased more than 10-fold from 2014 to 2019, and further growth is predicted (Statista, 2020). The UK's e-grocery market size is expected to increase from $\$ 14.6$

C John Olsson, Mary Catherine Osman, Daniel Hellström and Yulia Vakulenko. Published by Emerald Publishing Limited. This article is published under the Creative Commons Attribution (CC BY 4.0) licence. Anyone may reproduce, distribute, translate and create derivative works of this article (for both commercial and non-commercial purposes), subject to full attribution to the original publication and authors. The full terms of this licence may be seen at http://creativecommons.org/licences/by/4.0/ legalcode

The authors would like to thank vinnova (Sweden's innovation agency) for funding this research (grant number 2017-03457). The APC was funded by Lund University.

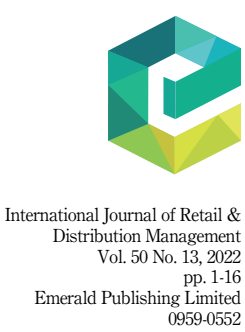

DOI 10.1108/IJRDM-07-2020-0273 
IJRDM 50,13

billion US dollars in 2018 to $\$ 22.1$ billion by 2023 (Statista, 2018). Likewise, forecasts by IDG (2018) project strong growth in several e-grocery markets, with a compound annual growth rate of about $20 \%$ in the US and Germany by 2023. During the COVID-19 pandemic, e-grocery sales were further accelerated, as social distancing measures spurred consumers to shop for groceries online. Fabric (2020) reported that US consumers nearly doubled their online grocery spending during the pandemic. Because this unprecedented growth has catapulted the market three or four years forward within just a few months, logistics and supply chain operations are now under overwhelming stress.

In e-grocery, last mile delivery is a major challenge due to product idiosyncrasies, including food safety, quality, sensitivity to temperature, shelf life and relatively low item value. Retailers offer e-grocery delivery using click-and-collect models, which require consumers to pick up their orders from a store or pick-up point. Additionally, if retailers offer home delivery, then consumers must be home during certain time slots to receive their orders. Given these limitations, retailers are pursuing new technological solutions and the development of unattended delivery services, such as in-car or in-fridge delivery. For example, online retailer Amazon now offers an unattended delivery service that allows couriers to access consumers' homes with digital locks and cameras (Amazon, 2020). Compared to home delivery, unattended delivery is significantly more convenient for consumers, as they do not need to be at home. The drawbacks are usually the need for investment and the installation of reception facilities.

As an emerging topic in retail research, last mile delivery is generally studied in relation to omnichannel development, changing demographics and changing consumer behaviour. Last mile delivery is often described as the most complicated, expensive and inefficient part of the supply chain (Gevaers et al., 2014). Despite these challenges, last mile delivery has become a source of market differentiation for retailers (Lim et al., 2017). Recent research highlights that last mile delivery is an important interface between the online shopping experience and customer satisfaction (Vakulenko et al., 2019). Research in unattended grocery delivery has addressed operating costs (Punakivi and Tanskanen, 2002; Punakivi et al., 2001), environmental impacts (Siikavirta et al., 2002) and security issues (Mckinnon and Tallam, 2003).

Consumer research on this phenomenon is still in its infancy. Using a questionnaire with 125 consumers and 15 e-retailers, Xu et al. (2008) investigated the perception of unattended delivery services. They found that the retailers' delivery options were not aligned with consumer preferences. Furthermore, they claimed that UK consumers favoured collection and delivery points over unattended home delivery. In a survey of French consumers, Goethals et al. (2012) observed that some customer groups were both interested in adopting unattended home delivery and reluctant to pay for it. Despite the contributions of these studies, little is known about customer expectations of unattended grocery delivery services.

Customer expectations serve as a standard against which ensuing experiences are compared to evaluate satisfaction or quality (Rodrígues del Bosque et al., 2006; Oliver and Winer, 1987). Therefore, an in-depth understanding of customer expectations is crucial for understanding the consumer perspective. Such insights will guide future consumer research and improve unattended home delivery practices (Punakivi et al., 2001; Goethals et al., 2012). Hence, a multiple case study of potential early adopters was conducted to explore customer expectations of unattended grocery delivery services. In particular, the study aimed to map the forms and determinants of their service expectations. The analysis was guided by the following two research questions:

$R Q 1$. What do consumers expect from unattended grocery delivery services?

$R Q 2$. How do consumers form service expectations of unattended grocery delivery services? 
This article is organised as follows. First, a theoretical background of customer experiences of both e-grocery and grocery delivery services is provided. Then the methodology behind the multiple case study is described. Data were collected from 10 Swedish households using semistructured interviews and direct observations. Next, a conceptual model and six propositions are presented based on the results, which show that consumers expect a combination of service forms. Finally, the implications of this work for researchers and retail managers, its limitations and future research opportunities are discussed.
Expectations of unattended grocery delivery

\section{Theoretical background}

\subsection{Customer experience in e-grocery}

Due to spreading Internet penetration, global economic growth and e-commerce development, e-retail has formed well-defined branches for particular products and services as well as their respective consumer groups. Because the e-grocery market developed rapidly, academic studies and industrial trials in previous decades have investigated grocery retail strategies, customer relationship management and business model engineering (Binkley and Connor, 1998; Kim and Park, 1997). Following retail research trends, grocery retail studies have recently focused on optimisation and branding, which include topics such as pricing strategies, merchandise optimisation, firm-centric perspectives and online appearances (Jensen and Grunert, 2014; Kwak et al., 2015; Leszczyc et al., 2000).

The shift towards service- and customer-centric models means that recent studies prioritise the customer, particularly the customer experience and journey (Lemon and Verhoef, 2016; Vargo and Lusch, 2004, 2008). By understanding how the customer creates value and forms expectations of a product or service, an organisation can better achieve customer satisfaction and loyalty. Value creation was once thought to be a linear process designed and managed by the firm. Its creation is now accepted to be both continuous and dynamic, occurring at every consumption stage and resulting in an eventual comparison of pre- and post-purchase evaluations, and thus value creation strongly relies on the consumer (Normann and Ramirez, 1993; Parasuraman, 1997; Tynan et al., 2014).

Due to the embedded differences between traditional physical outlets and online grocery stores, the online-based customer experience inevitably has higher risks and greater considerations than the traditional experience. For example, online customers cannot check produce freshness and must consider the delivery conditions for various products (e.g. those that require freezing, refrigeration and certain ambient temperatures). Managing customer experience and expectations is crucial for grocery e-retailers (Wilson-Jeanselme and Reynolds, 2006; Kureshi and Thomas, 2019; Singh, 2019). These two factors are further intensified by the changing market environment, which is fuelled by innovations in technology, service design and marketing (Demoulin and Djelassi, 2016; Hagberg et al., 2016; Pinto et al., 2017; Reinartz et al., 2019). Technological advancements in e-retail have drastically changed how customers participate in value creation. Because customers have become more involved in the structure of the product or service, they act as co-producers of value and thus perceive and create value differently (Flores and Vasquez-Parraga, 2015). Online retailers must understand customer expectations to perform well in growing e-grocery markets, as these relatively new markets can still transform in unpredictable ways.

\subsection{Customer expectations and delivery service}

Although customer expectations are rooted in the pre-purchase stage, they also affect the later purchase and post-purchase stages, and re-purchase experience. Given that some touchpoints throughout the customer journey are managed by the offer provider and the external partners, retailers can influence customer satisfaction and ultimately loyalty 
IJRDM 50,13

(i.e. purchase and repurchase; Lemon and Verhoef, 2016). The pre-purchase stage is arguably the most intricate part of customer experience design and management, as within it the customer develops sequential expectations towards the offer and its associated services. Customer expectations management becomes even more complex when service design and delivery are split between several actors. This is the case with e-grocery, as a third-party logistics provider generally delivers orders while the e-retailer supervises how customer expectations are formed during the pre-purchase and purchase stages.

Rooted in cognitive dissonance theory (Festinger, 1957) and the disconfirmation paradigm (Oliver, 1980), several conceptual models and theories have been developed to examine how customer expectations affect retail purchases. When the expectation disconfirmation approach was used to analyse consumer retail service experience, the results indicated that both expectations and (dis)confirmation directly impacted customer satisfaction (Swan and Trawick, 1981; Holak et al., 1987). In practical terms, this means that when a consumer places an online grocery order, this consumer may develop expectations towards the quality of the chosen products and the delivery experience. Specifically, the products should be delivered in accordance with their temperature requirements and within the promised time window. When the consumer compares the actual experience to these expectations, they will reach a certain satisfaction level. Because the online retail environment relies more on customer trust towards the offer and retailer image than the traditional brick-and-mortar environment, paradigm and service expectation-related theories are suitable for the e-retail context (Mitra and Fay, 2010).

Customer expectations change across the experience continuum, and the three mostresearched expectation types are expected standard, predictive expectation and desired expectation. Expected standard refers to the plausible performance level (Miller, 1977), predictive expectation to the anticipated performance level (Prakash, 1984; Swan and Trawick, 1980) and desired expectation to the performance level that the customer hopes the product or service will reach (Swan and Trawick, 1980). These expectation types can be formed through different means, such as a comparison of similar products, prior beliefs of a product or service from advertisement or word of mouth as well as personal desires or goals for how the product or service may affect their life (Assouad and Overby, 2016; Nicolae et al., 2013).

Zeithaml et al. (1993) proposed a model of the creation of service expectations with three service levels: desired service, adequate service and predicted service. The desired and predicted services in this model are the same as desired and predictive expectations. Adequate service refers to the service level that customers are "willing to accept" (Zeithaml et al., 1993, p. 6). Each service expectation is affected by various determinants: desired service is affected by personal needs and enduring service intensifiers; adequate service by transitory service intensifiers, perceived service alternatives, self-perceived service role and situational factors and lastly predicted service by explicit service promises, implicit service promises, word of mouth and past experience (Ziethaml et al., 1993). Exhaustive models are particularly relevant to customer expectations of e-grocery delivery services, as the consumer's psychology, decision-making process and expectations are stimulated by many touchpoints from market actors prior to the delivery experience.

\section{Methodology}

Since customer expectations of unattended grocery delivery services represent an uncharted territory in last mile delivery, an exploratory approach was adopted based on multiple cases as suggested by Eisenhardt (1989). The case study methodology is particularly suitable for exploratory research on emerging phenomena and practices (Meredith, 1998) and wellestablished in retail distribution and management research (Hellström and Nilsson, 2011; 
Wollenburg et al., 2018; Eriksson, 2019; Buldeo Rai et al., 2019). Adopting a case study approach allows gaining the in-depth insights necessary to understand the contemporary phenomenon of unattended delivery services in their real-life context. Yin (2018) highlights that case study research is suitable for phenomena over which the researcher has little or no control. Purposive sampling was used to select early adopters, an interesting group to explore customer expectations of this emerging service. Data were collected from semi-structured interviews and direct observations. The data were analysed using both open-coding and $a$ priori coding, which resulted in a set of propositions about the forms and determinants of customer expectations of unattended delivery services.

\subsection{Case study design and selection}

Multiple case studies are often considered to be more robust than single case studies (Herriott and Firestone, 1983), as they can improve external validity and mitigate observer bias (Voss et al., 2002). However, multiple case studies are also more resource- and time-consuming to implement (Yin, 2018) and risk reducing the depth of the analysis when resources are constrained (Voss et al., 2002). While the number of cases necessary for theory building varies, Eisenhardt (1989) recommended four to ten cases. Ten cases (cases A-J) were chosen because this number provides sufficient grounding for theory building with limited complexity.

Together with the other Nordic countries and the UK, Sweden has one of the highest ecommerce penetration rates in Europe. In the e-grocery sector, this penetration rate is still relatively low compared to those of developed non-European countries, and yet it is also rapidly growing (Postnord, 2020). Every year, more Swedish consumers purchase their groceries online through either their local grocer or an online retailer. Currently, there are no unattended grocery delivery options available in Sweden. Consumers must either choose a delivery time slot or have the order left outside their home. Therefore, Sweden provides an interesting context for the study because of its position in the e-grocery market and lack of an unattended delivery service.

To map the service expectations of potential early adopters, purposive sampling was used following the recommendations of Ellram (1996). Focusing on a specific population can increase external validity when theory building with case studies (Eisenhardt, 1989). Early adopters are an interesting group to investigate due to the novelty of open-system unattended delivery services. According to Rogers (2003), adopter and innovation characteristics are important predictors of innovation adoption. Previous studies have identified several socioeconomic characteristics of early adopters of various innovations (Campbell et al., 2012; Kim and Park, 2014; Plötz et al., 2014; Vassileva and Campillo, 2017). E-grocery shopping is most likely to be adopted by people who live in urban areas, have relatively high incomes and are active online shoppers, including families with young children, households without cars and individuals who have a special diet or interest in specialty cuisine (Murphy, 2007; Van Droogenbroeck and Van Hove, 2017).

Ten cases were selected from a pool of households based on these reported socio-economic factors. All selected households had extensive e-commerce experience and previously reported interest in participating in a pilot project for unattended delivery boxes, which provided support that the selected households were potential early adopters of the service. Nine of the selected households consisted of two adults and two underage children, and the tenth household consisted of only two adults. Both adults were employed, and each household income was relatively high. All households were located in the suburbs of Helsingborg, Sweden.

\subsection{Data collection}

Data were collected using semi-structured interviews and direct observations. Yin (2018) emphasised that the interview is a crucial source of case study evidence. Therefore, one researcher conducted semi-structured interviews between February and April 2019. Ten
Expectations of unattended grocery delivery 
IJRDM 50,13 semi-structured interviews were conducted with 1-2 individuals per case (respondents A-J, corresponding to the ten cases), covering four sections: household dynamics, grocery shopping habits, comfort with technology use and expectations of the delivery service. The interviews were conducted face-to-face and generally lasted between 30 and $45 \mathrm{~min}$. All interviews were recorded with the explicit permission of the interviewees and transcribed verbatim and word-by-word. To ensure construct validity, one investigator checked the transcriptions against the recordings (Tracy, 2013; Brinkmann and Kvale, 2015). Any discrepancies were immediately corrected in the interview transcripts. The interviews were conducted, transcribed and coded in English. Prior to the interviews, an interview guide was developed and tested based on literature from various research areas, such as customer value creation and customer expectations. Two pilot interviews were conducted before primary data collection, and the interview guide was adjusted accordingly.

In addition, direct observations were made to gain a holistic understanding of the individual cases. According to Yin (2018), direct observations for a case study can range from formal observations, which adhere to the case protocol, to casual observations, which are often made during fieldwork. In this study, casual observations were used that targeted the immediate environment of each household. These additional data help to validate the insights gained from the interviews and increase construct validity (Eisenhardt, 1989). As suggested by Yin (2018), case study protocols were utilised to guide the researchers and a case study database was used to increase the reliability of the findings.

\subsection{Data analysis}

The within-case analysis began by writing up the cases to generate internally consistent descriptions of each case (Eisenhardt, 1989). Moreover, rich descriptions of the respective households were created based on data collected from the interviews and observations. The cross-case analysis was conducted to search for patterns among the households (Eisenhardt, 1989; Yin, 2018) and compared the findings from the within-case analysis. The interview transcripts were coded in the qualitative data analysis support software NVIVO 12. Two investigators coded the transcripts independently to ensure the internal validity of the findings. One investigator used a priori coding based on the model by Zeithaml et al. (1993), while another investigator used open-coding and axial coding inspired by grounded theory (Corbin and Strauss, 2008). The open coding allowed themes to emerge from the transcripts. Each theme was linked to the original phrases in the transcripts for the sake of transparency. Axial coding was used to relate identified themes and concepts to each other and conduct synthesis (Corbin and Strauss, 2008). Finally, three investigators compared the outcome from the two coding procedures until consensus on the empirical patterns found was reached (i.e. intercoder agreement checks). All themes and concepts identified from both procedures were merged and synthesised, see Appendix (Table A1). Ultimately, propositions were derived from the patterns found during data analysis.

\subsection{Research quality}

This case study followed well-established principles of research quality and rigor to establish trustworthiness throughout the research process. Research quality is a multi-dimensional concept often judged in qualitative methodology in the terms of construct validity, internal validity, external validity and reliability (Gibbert and Ruigrok, 2010; Meredith, 1998; Yin, 2018). To ensure rigor in the data collection and analysis, multiple tactics and associated measures appropriate for case study research were employed (see Table 1).

\section{Results}

This research offers a conceptual model (Figure 1) that contributes to understanding what consumers expect from unattended delivery services and how they form these expectations. 
Trustworthiness criteria

Construct validity

Accuracy with which the study measures the intended construct

\section{Internal validity}

Extent to which the study establishes a trustworthy causal relationship
Tactics

Implemented measures

- Data triangulation

- Establish a chain of evidence

- Pattern matching

- Explanation building

- Logic models

- Rival explanations

\section{External validity}

Extend to which the study findings can be applied to the populations and the settings of interest, establishes a domain in which findings can be analytically generalised

\section{Reliability}

Consistency and repeatability of study findings
- Use replication logic

- Provide rationale for selection of cases

- Use a case study protocol

- Develop a case study database

- Establish a chain of evidence
- Data were collected from both semistructured interviews and observations

- Investigator checked interview transcripts against recordings

- Multiple investigators analysed the data independently

- Systematically investigated patterns within and across cases

- Systematic combining of theory and empirical case data in developing a logic model for expectations

- Carefully developed propositions and examined alternative propositions

- Research design is based on literal and theoretical replication

- Purposive sampling was employed with pre-defined criteria for selection of early adopters

- Maintained detailed case study protocols

- Created and systematically organised a case study database containing descriptions of individual cases, recordings and transcriptions, Trustworth. Table 1. memos and notes, as well as codes

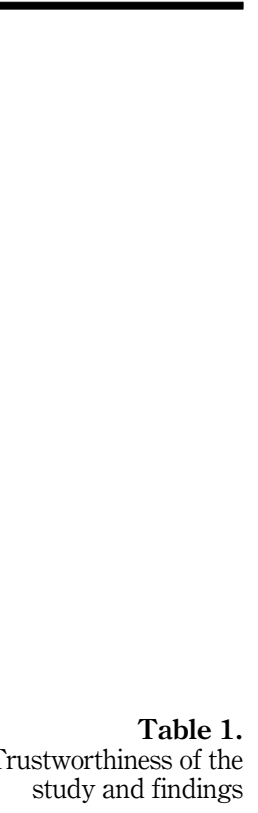

Expectations of unattended grocery delivery

Determinants

Service Expectations

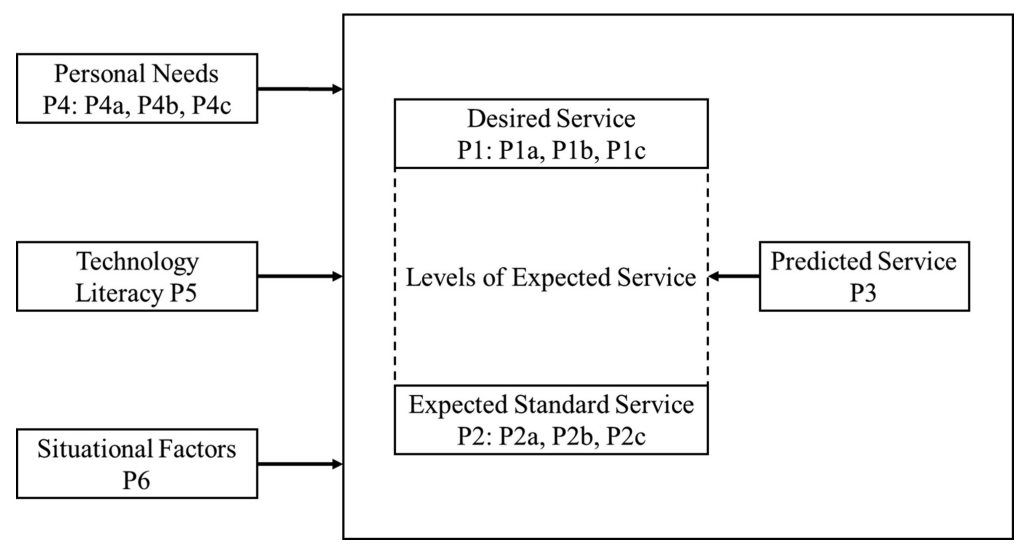

Figure 1.

Customer expectation components of unattended grocery delivery services 
IJRDM

50,13

8

The model shows that there are three types of service expectations, i.e. desired service, expected standard service and predicted service. The empirical evidence reveals that these service expectations take various forms and that the combination of these forms sets the expectation level of unattended delivery services. Furthermore, the study identifies three determinants: personal needs, technology literacy, and situational factors. The following section lays out the case study findings and provides a set of propositions on the forms and determinants of customer expectations in unattended grocery delivery.

\subsection{Desired service}

Desired service describes the wishful forms of service that customers perceive as "nice to have". The case study reveals that users of unattended grocery services desire integrated returns, an open system accessible by various retailers and service providers as well as a nondescript design for their delivery hardware. Following previous research (Swan and Trawick, 1981), it seems that while consumers will understand if their desired services cannot be offered, their overall satisfaction will likely increase if these services become available. This led the first proposition.

$P 1$. Consumers expect a combination of forms in their desired service for unattended grocery delivery services.

One form desired by the participants was a seamless shopping experience. More specifically, a clear pattern is that the participants wished for integrated returns, and this desire was expressed in relation to fashion deliveries, which typically have return rates of between 20 and $60 \%$ depending on product characteristics (Cullinane et al., 2019). For example, Respondent $\mathrm{B}$ describes a desire of returning products as an integrated part of unattended delivery services: "Yeah, is it supposed to in [the] future, you know, [be like] if [.. .] I buy a dress and it does not fit [?] Can I put in our return in the box [. . .]?'. Hence, the following proposition was developed:

P1a. Consumers desire integrated returns in unattended grocery delivery services.

Another desired form was the integration of various retailers and logistics service providers. During the interviews, the households strongly expressed their desire to use unattended delivery services for items besides groceries, such as books and clothes. Respondent $\mathrm{C}$ provides evidence that households want to use unattended delivery services for a wide range of items, stating "I really hope that I can use my [box] [for] more than groceries. That's what Im really hoping for, when I can buy everything online [.. .] [and] get everything delivered to it. That's the real thing for me". Further evidence is provided by Respondent $\mathrm{E}$, echoing this idea: "Then that [product] would be easier to order and things such as books as well [...]. I do not know if that's a possibility [...] straight away but [maybe] in the future". Ultimately, as the households wanted unattended delivery services to use an open system, the following proposition was formulated:

\section{$P 1 b$. Consumers desire an open system for unattended grocery delivery services.}

Because the tangible aspects of a service both influence perceived service quality and create service expectations, e-grocery services should take the design of the unattended delivery box into account (Parasuraman et al., 1988). The case study shows that the households were concerned about the box's appearance, as it would be located outside their homes and visible from the street. Consequently, respondents wanted it to blend in with the facade and surrounding environment. Respondent D explains this desire as follows: "[...] it's not a concern[,] but it's just how it will it look because it will be standing outside and so on[.] [. . . Jit will [be visible,] and I guess at first you will react [to] it, but then it will [blend in]'. Hence, the following proposition was created: 
P1c. Consumers desire nondescript designs for the hardware used in unattended grocery delivery services.

\subsection{Expected standard service}

Expected standard service is the minimum service that consumers expect. In contrast to desired service, consumers will not accept a product or system if their expected standard services cannot be offered. The case study findings indicate that households expect unattended grocery delivery to help them save time, gain flexibility and benefit from the ease of use of the service. These expectations are derived from the consumers' need for service convenience, which influences their evaluation of service eligibility. Based on the multiple cases, a combination of these forms of expected standard service is necessary for consumers to accept the service. Therefore, the following proposition was formulated:

P2. Consumers expect a combination of forms of expected standard service in unattended grocery delivery services.

The participants, indicative of early adopters, had busy lifestyles with little spare time due to work, family and personal activities. A significant number of households did not want to spend time picking up orders from pick-up points or shopping for groceries in physical stores. Respondent C emphasises this: "My [hope] is [to spend] more time cooking dinner than shopping [for] it". The households intended to spend the time saved with the service on other activities, such as preparing dinner. Given that the expectation of saving time was a common pattern among the cases, the following proposition was created:

$P 2 a$. Consumers expect to save time by using unattended grocery delivery services.

Flexibility refers to the capability of being readily changed, meaning participants expected to spontaneously adjust their plans without compromising service. Given that early adopters typically lead hectic lives, the participants logically wanted unattended delivery services to improve their flexibility. Respondent $\mathrm{H}$ emphasises that flexibility even refers to using home delivery rather than a pick-up point: "Flexibility and convenience. [.. .] you shop more and more on Internet, and this [. . . w will give you [the] opportunity to have it delivered to your home instead of going to the [drop-off] places [in] the stores where you collect your packages that you buy right now. So, I think it will increase the Internet shopping even more". A clear pattern from multiple cases is that flexibility is necessary for households to accept the service. Hence, the following proposition was formulated:

$P 2 b$. Consumers expect to gain flexibility by using unattended grocery delivery services.

The participants also expected the services to be intuitive and simple. Some households wanted everything to work without them having to read manuals. For example, respondent $F$ asserted, "But I just want it to work. I do not want to read these difficult manuals. I just want to open [it] up, and then I shall understand what to do. And then it works ...". The case study shows that the participants highly valued ease of use, demonstrated in the following proposition:

\section{P2c. Consumers expect ease of use in unattended grocery delivery services.}

\subsection{Predicted service}

Consumers make predictions before encountering a service, which can originate from previous experiences, advertisements or word-of-mouth. With the adoption of an innovative service, consumers predict a certain level of security for the service. When introduced to new services that have the potential to breach perceived security, consumers have previously
Expectations of unattended grocery delivery 
IJRDM

50,13

been wary of those security levels (Mckinnon and Tallam, 2003). In contrast, the case study evidence suggests that the opposite applies to unattended grocery delivery. Namely, none of the cases had concerns about security. For example, respondent A states that "It's quite safe". Further, respondent H asserts "I mean, I expect that the product will be secure. Yeah, that [someone] will not be able to break in". Since the study reveals that the households expected the service to be secure, the corresponding proposition was put forward:

P3. Consumers predict a sufficient level of security for unattended delivery services.

\subsection{Personal needs}

A consumer's personal needs consist of their prioritised aspects of physical and psychological well-being. When a service does not assist a consumer in meeting their identified personal needs, this consumer will seek out alternate services or products instead. Based on the case study, three forms of personal needs in unattended grocery delivery services were found: reducing stress, limiting social interaction and increasing spare time. Therefore, the following proposition is formulated:

$P 4$. Consumers' personal needs elevate their expectations of unattended grocery delivery services.

Evidence from the interviews revealed several plausible stressors that can arise when grocery shopping, which affect the well-being of both individual consumers and their households. For example, respondent B describes that they found taking the children to the store to be stressful, "I do not like taking the kids to the store. I think it's chaotic". Respondent C further acknowledges, "It's when you have to go to into the car on Monday [and] go down to Coop with two tired children, then it's starting to get a little bit 'ugh". The findings from comparing the cases show that a personal need for stress reduction was a strong pattern. Therefore, the following proposition is put forward:

$P 4 a$. Consumers have a personal need for stress reduction in grocery shopping.

The study findings indicate that respondents identified social interactions such as talking with neighbours or service personnel as inevitable when grocery shopping and avoidable when using unattended grocery delivery. Respondent $\mathrm{F}$ describes a preference for not talking to others in the store, "No, I do not chitchat in the store. That's not me". Further support is provided by respondent J who found talking to other shoppers inconvenient: "So often there comes persons to [my wife] [...] to discuss, say hello, former students and so on [.] So, I [...] think that that is also one of the things that takes a lot of time from us [...]. I think that she will have a big benefit of not being forced [...], I mean [into talking]". Overall, the case study suggests that participants had a need to avoid social interactions when grocery shopping:

$P 4 b$. Consumers have a personal need to limit social interaction in grocery shopping.

Early adopters of e-grocery delivery services generally prioritise activities other than grocery shopping, such as personal hobbies or spending time with family. Some households prioritised meal preparation and eating together, while others preferred doing sports or watching movies. These household interactions are arguably crucial to the well-being of its individuals. Respondent E describes a need to spend more time with the family: "Yeah, exactly. Share the day. So that's nice, so you do that and nothing else. Usually one of the kids helps out". In addition, respondent $\mathrm{H}$ highlights the importance of having time for spare time activities such as sports: "We are a very active family. We do a lot of training both me and the kids, so almost every day we have a sport". Because the case study demonstrates that participants desired to spend more time on activities other than grocery shopping, the following proposition was formulated: 
P4c. Consumers have a personal need to increase spare time and decrease time spent grocery shopping.

\subsection{Technology literacy}

Unattended grocery delivery services require technology literacy, meaning an individual's ability to effectively use and fluidly adapt to new technology (Hansen, 2003). Service expectations are affected by how comfortable a consumer is with planning and ordering items from an online platform, using a mobile application and using technology in general. The majority of households did not consider their own technology literacy to be an obstacle. For example, respondent $\mathrm{H}$ described a high degree of technology literacy: "I use the phone all the time to buy stuff'. Respondent $\mathrm{G}$ provides further support, describing that they were comfortable using their smartphones on a daily basis including various applications. In addition, respondent I emphasised how their profession has fostered technology literacy. The case study evidence suggests that technology literacy has positively affected expected service. Therefore, the following proposition was created:

P5. Consumers' technology literacy raises their expectations of unattended grocery delivery services.

\subsection{Situational factors}

In multiple cases it was evident that how a service responds to situational factors, such as unexpected changes to personal plans, can increase service expectations. In connection with the daily stress triggers discussed earlier, the majority of households reported that their schedules could change unexpectedly, which made it difficult to plan grocery deliveries. For example, respondent J highlighted the importance of unexpected changes: "Stuff happens with the kids, [ike] that they want to play and we have to go to get them and so on, so we feel that we get stuck at home when we have delivered a food order [somewhere else]". In addition, respondent $\mathrm{B}$ describes a typical situation when their plans changed suddenly while waiting for delivery which they handled by putting a note on the front door. Overall, the study finds that participants desired an unattended delivery service that could operate independently from their schedules. Accordingly, the following proposition was formulated:

P6. Consumers' expectations of unattended grocery delivery services are elevated by situational factors.

\section{Conclusions}

This multiple case study sheds light on customer expectations of unattended delivery services. The study findings offer a conceptual model (Figure 1) that represents the relationship between forms and determinants of service expectations. The study reveals various forms of desired service, expected standard service and predicted service in unattended grocery delivery. Findings suggests that customers desire open access features from retailers and services providers, integrated product returns services and nondescript hardware designs. The study offers significant insights into expected standard service, demonstrating that customers expect to save time, gain flexibility and benefit from the ease of use of the service. Moreover, the study shows that customers predict sufficient security of unattended delivery services. The empirical evidence shows that these service expectations are determined by personal needs, technology literacy and situational factors. The identified personal needs are stress reduction, limiting social interaction and increasing spare time.

This research has several theoretical implications. First, consistent with the work of Zeithaml et al. (1993), this research (re)verifies the nature and determinants of customer
Expectations of unattended grocery delivery 
IJRDM 50,13

expectations and extends the notion to include the context of unattended grocery delivery services. This contribution is particularly valuable because delivery service is often thought of in logistics and operational terms but rarely in terms of fulfilling customer expectations. Second, the study contributes to the literature by recognising customer expectations as an integral part of the prepurchase stage in the customer journey. Specifically, this research adds to the body of customer journey literature by identifying consumer needs (Propositions 4a-4c) as well as forms of service expectations (Propositions 1a-1c, 2a-2c, and 3). Future research is encouraged to test these propositions using a quantitative approach and further exploring how expectations affect customer experience in the later purchasing stages of the customer journey. Third, this research contributes to the niche intersection between e-grocery and consumer research. The case study provides novel consumer insights into delivery service in the rapidly growing e-grocery sector. Consistent with the work of Singh (2019) and WilsonJeanselme and Reynolds (2006), the study re-emphasises the importance of delivery for service excellence in e-grocery retail. Finally, this research adds to last mile delivery literature by exploring an emerging technology-enabled delivery service. Specifically, this study adds to the seminal work of Mckinnon and Tallam (2003) by demonstrating that customers predict sufficient security of unattended delivery services (Proposition 3).

Several managerial implications can be gained from the results of this study. First, the conceptual model implies that retailers and logistics service providers need to understand customers' personal needs, technology literacy and situational factors as these determinants affect service expectations. Managers should use these insights to establish a better fit between service offering and customer expectations. Second, retail managers are encouraged to measure customer expectations to gain insights into the levels of desired service, expected standard service and predicted service. The conceptual model and the propositions of this study build a basis for measuring the level of service expectations. The forms of customer expectations require further operationalisation to measure the level of service expectations. Third, findings can guide the design and formation of unattended grocery delivery services. In particular, managers at logistics service providers can use the conceptual model and the propositions to align their operations with customer expectations. Further research is required to explore how the fulfilment of service expectations affects customer experience.

As any research, this study has limitations. Case study research is highly context dependent, this study was conducted on early adopters in Sweden. For example, the effect of the Swedish context can be seen in the identified personal need to limit social interactions in grocery shopping (Proposition 4b). This proposition appears unique to the Swedish context and highlights the need to study customer expectations of unattended delivery services in a broader context. Further research could add insights from different consumer groups, as well as other geographical and cultural contexts. Moreover, case study research cannot infer how strongly the three individual determinants affect service expectations. Quantitative research methods could better address the nature, scope and strength of these determinants. Finally, quantitative research could contribute to the understanding of the topic by testing the propositions provided by this research.

\section{References}

Amazon (2020), “Amazon.com help: key by Amazon smart lock kit”, available at: https://www.amazon. com/gp/help/customer/display.html?nodeId=202179650 (accessed 11 March 2020).

Assouad, A. and Overby, J. (2016), "The impact of culture on customer expectations", Journal of Management Policy and Practice, Vol. 17 No. 2, pp. 19-32.

Binkley, J.K. and Connor, J.M. (1998), "Grocery market pricing and the new competitive environment", Journal of Retailing, Vol. 74 No. 2, pp. 273-294. 
Brinkmann, S. and Kvale, S. (2015), Interviews: Learning the Craft of Qualitative Research Interviewing, Sage Publications, Thousand Oaks, CA.

Buldeo Rai, H., Mommens, K., Verlinde, S. and Macharis, C. (2019), "How does consumers' omnichannel shopping behaviour translate into travel and transport impacts?: case-study of a footwear retailer in Belgium”, Sustainability, Vol. 11, p. 2534.

Campbell, A.R., Ryley, T. and Thring, R. (2012), "Identifying the early adopters of alternative fuel vehicles: a case study of Birmingham, United Kingdom", Transportation Research Part A: Policy and Practice, Vol. 46, pp. 1318-1327.

Corbin, J. and Strauss, A. (2008), Basics of Qualitative Research: Techniques and Procedures for Developing Grounded Theory, 3rd ed., Sage Publications, Thousand Oaks, CA.

Cullinane, S., Browne, M., Karlsson, E. and Wang, Y. (2019), "Retail clothing returns: a review of key issues", in Wells, P. (Ed.), Contemporary Operations and Logistics: Achieving Excellence in Turbulent Times, Springer International Publishing, Cham, pp. 301-322.

Demoulin, N.T.M. and Djelassi, S. (2016), "An integrated model of self-service technology (SST) usage in a retail context", International Journal of Retail and Distribution Management, Vol. 44 No. 5, pp. 540-559.

Eisenhardt, K.M. (1989), "Building theories from case study research", Academy of Management Review, Vol. 14, pp. 532-550.

Ellram, L.M. (1996), "The use of the case study method in logistics research", Journal of Business Logistics, Vol. 17 No. 2, pp. 93-138.

Eriksson, E. (2019), “Contextual adaptation of omni-channel grocery retailers' online fulfilment centres", International Journal of Retail and Distribution Management, Vol. 47, pp. 1232-1250.

Fabric (2020), "The impact of Covid-19 on online grocery", available at: https:/getfabric.com/theimpact-of-covid-19-on-online-grocery/ (accessed 25 June 2020).

Festinger, L.A. (1957), A Theory of Cognitive Dissonance, Stanford University Press, Stanford, CA.

Flores, J. and Vasquez-Parraga, A.Z. (2015), "The impact of choice on co-produced customer value creation and satisfaction", Journal of Consumer Marketing, Vol. 32 No. 1, pp. 15-25, doi: 10.1108/ JCM-04-2014-0931.

Gevaers, R., Van De Voorde, E. and Van Elslander, T. (2014), "Cost modelling and simulation of lastmile characteristics in an innovative B2C supply chain environment with implications on urban areas and cities", Procedia - Social and Behavioral Sciences, Vol. 125, pp. 398-411.

Gibbert, M. and Ruigrok, W. (2010), “The 'What' and 'How' of case study rigor: three strategies based on published work", Organizational Research Methods, Vol. 13 No. 4, pp. 710-737.

Goethals, F., Leclercq-Vandelannoitte, A. and Tütüncü, Y. (2012), "French consumers' perceptions of the unattended delivery model for e-grocery retailing", Journal of Retailing and Consumer Services, Vol. 19 No. 1, pp. 133-139.

Hagberg, J., Sundström, M. and Nicklas, E.Z. (2016), "The digitalization of retailing: an exploratory framework", International Journal of Retail and Distribution Management, Vol. 44 No. 7, pp. 694-712.

Hansen, J. (2003), “To change perceptions of technology programs”, The Journal of Technology Studies, Vol. 29, p. 116.

Hellström, D. and Nilsson, F. (2011), "Logistics-driven packaging innovation: a case study at IKEA", International Journal of Retail and Distribution Management, Vol. 39, pp. 638-657.

Herriott, R.E. and Firestone, W.A. (1983), "Multisite qualitative policy research: optimizing description and generalizability", Educational Researcher, Vol. 12, pp. 14-19.

Holak, S.L., Lehmann, D.R. and Sultan, F. (1987), "The role of expectations in the adoption of innovative consumer durables: some preliminary evidence”, Journal of Retailing, Vol. 63 No. 3, pp. 243-259.

Expectations of unattended grocery delivery 
IJRDM 50,13

IGD (2018), "Leading global online grocery markets to create a $\$ 227 \mathrm{bn}$ growth opportunity by 2023 ", available at: https://www.igd.com/articles/article-viewer/t/leading-global-online-grocerymarkets-to-create-a-227bn-growth-opportunity-by-2023/i/20396 (accessed 06 Jul 2020).

Jensen, B.B. and Grunert, K.G. (2014), "Price knowledge during grocery shopping: what we learn and what we forget", Journal of Retailing, Vol. 90 No. 3, pp. 332-346.

Kim, B.D. and Park, K. (1997), "Studying patterns of consumer's grocery shopping trip”, Journal of Retailing, Vol. 73 No. 4, pp. 501-517.

Kim, M.-J. and Park, J. (2014), "Mobile phone purchase and usage behaviours of early adopter groups in Korea”, Behaviour and Information Technology, Vol. 33, pp. 693-703.

Kureshi, S. and Thomas, S. (2019), "Online grocery retailing-exploring local grocers beliefs", International Journal of Retail and Distribution Management, Vol. 47 No. 2, pp. 157-185.

Kwak, K., Duvvuri, S.D. and Russell, G.J. (2015), “An analysis of assortment choice in grocery retailing”, Journal of Retailing, Vol. 91 No. 1, pp. 19-33.

Lemon, K.N. and Verhoef, P.C. (2016), "Understanding customer experience throughout the customer journey”, Journal of Marketing, Vol. 80 No. 6, pp. 69-96.

Leszczyc, P.T.P., Sinha, A. and Timmermans, H.J.P. (2000), "Consumer store choice dynamics: an analysis of the competitive market structure for grocery stores", Journal of Retailing, Vol. 76 No. 3, pp. 323-345.

Lim, S., Wang, L. and Srai, J. (2017), "Wal-Mart's omni-channel synergy", Supply Chain Management Review, September/October, pp. 30-37.

Mckinnon, A.C. and Tallam, D. (2003), "Unattended delivery to the home: an assessment of the security implications", International Journal of Retail and Distribution Management, Vol. 30 No. 1, pp. 30-41.

Meredith, J. (1998), "Building operations management theory through case and field research", Journal of Operations Management, Vol. 16, pp. 441-454.

Miller, J.A. (1977), "Studying satisfaction, modifying models, eliciting expectations, posing problems, and making meaningful measurements", in Hunt, H. (Ed.), Conceptualization and Measurement of Consumer Satisfaction and Dissatisfaction, Marketing Science Institute, Cambridge, MA, pp. 72-91.

Mitra, D. and Fay, S. (2010), "Managing service expectations in online markets: a signaling theory of e-tailer pricing and empirical tests", Journal of Retailing, Vol. 86 No. 2, pp. 184-199.

Murphy, A.J. (2007), "Grounding the virtual: the material effects of electronic grocery shopping", Geoforum, Vol. 38, pp. 941-953.

Nicolae, L.I., Tănăsescu, D. and Popa, V. (2013), “Customer expectations management”, Valahian Journal of Economic Studies, Vol. 4, pp. 91-100.

Normann, R. and Ramírez, R. (1993), "From value chain to value constellation: designing interactive strategy", Harvard Business Review, Vol. 71, pp. 65-77.

Oliver, R.L. (1980), “A cognitive model of the antecedents and consequences of satisfaction decisions”, Journal of Marketing Research, Vol. 17 No. 4, pp. 460-469.

Oliver, R.L. and Winer, R.S. (1987), "A framework for the formation and structure of consumer expectations: review and propositions", Journal of Economic Psychology, Vol. 8, pp. 469-499.

Parasuraman, A. (1997), "Reflections on gaining competitive advantage through customer value", Journal of the Academy of Marketing Science, Vol. 25, pp. 154-161.

Parasuraman, A., Zeithaml, V. and Berry, L. (1988), "SERVQUAL: a multiple-item scale for measuring consumer perceptions of service quality", Journal of Retailing, Vol. 64, pp. 12-40.

Pinto, G.L., Dell'Era, C., Verganti, R. and Bellini, E. (2017), "Innovation strategies in retail services: solutions, experiences and meanings", European Journal of Innovation Management, Vol. 20 No. 2, pp. 190-209. 
Plötz, P., Schneider, U., Globisch, J. and Dütschke, E. (2014), "Who will buy electric vehicles?: identifying early adopters in Germany", Transportation Research Part A: Policy and Practice, Vol. 67, pp. 96-109.

Postnord (2020), "E-Barometern (2019)", available at: https://www.postnord.se/vara-losningar/ehandel/e-handelsrapporter/e-barometern (accessed 11 March 2020).

Prakash, V. (1984), "Validity and reliability of the confirmation of expectations paradigm as a determinant of consumer satisfaction", Journal of the Academy of Marketing Science, Vol. 12, pp. 63-76.

Punakivi, M. and Tanskanen, K. (2002), "Increasing the cost efficiency of e-fulfilment using shared reception boxes", International Journal of Retail and Distribution Management, Vol. 30, pp. 498-507.

Punakivi, M., Yrjölä, H. and Holmström, J. (2001), "Solving the last mile issue: reception box or delivery box?", International Journal of Physical Distribution and Logistics Management, Vol. 31, pp. 427-439.

Reinartz, W., Wiegand, N. and Imschloss, M. (2019), "The impact of digital transformation on the retailing value chain", International Journal of Research in Marketing, Vol. 36 No. 3, pp. 350-366.

Rodríguez Del Bosque, I.A., San Martín, H. and Collado, J. (2006), "The role of expectations in the consumer satisfaction formation process: empirical evidence in the travel agency sector", Tourism Management, Vol. 27, pp. 410-419.

Rogers, E.M. (2003), Diffusion of Innovations, The Free Press, New York.

Siikavirta, H., Punakivi, M., Kärkkäinen, M. and Linnanen, L. (2002), "Effects of e-commerce on greenhouse gas emissions: a case study of grocery home delivery in Finland", Journal of Industrial Ecology, Vol. 6, pp. 83-97.

Singh, R. (2019), "Why do online grocery shoppers switch or stay?: an exploratory analysis of consumers' response to online grocery shopping experience", International Journal of Retail and Distribution Management, Vol. 47 No. 2, pp. 157-185.

Statista (2018), "Forecasted online grocery market size in selected European nations from 2018 to 2023", available at: https://www.statista.com/statistics/960484/online-grocery-market-sizeseurope/ (accessed 13 July 2020).

Statista (2020), "Gross merchandise volume of fresh food e-commerce in China from 2013 to 2019", available at: https:/www.statista.com/statistics/1026889/china-fresh-food-ecommerce-grossmerchandise-volume/ (accessed 25 June 2020).

Swan, J.E. and Trawick, I.F. (1980), "Satisfaction related to predictive vs desired expectations", Refining Concepts and Measures of Consumer Satisfaction and Complaining Behavior, Indiana University Press, Bloomington, IN, pp. 7-12.

Swan, J.E. and Trawick, I.F. (1981), "Disconfirmation of expectations and satisfaction with a retail service”, Journal of Retailing, Vol. 36 No. 3, pp. 350-366.

Tracy, S.J. (2013), Qualitative Research Methods: Collecting Evidence, Crafting Analysis, Communicating Impact, Wiley-Blackwell, West Sussex.

Tynan, C., Mckechnie, S. and Hartley, S. (2014), "Interpreting value in the customer service experience using customer-dominant logic", Journal of Marketing Management, Vol. 30, pp. 1058-1081.

Vakulenko, Y., Shams, P., Hellström, D. and Hjort, K. (2019), "Online retail experience and customer satisfaction: the mediating role of last mile delivery", The International Review of Retail, Distribution and Consumer Research, Vol. 29 No. 3, pp. 306-320.

Van Droogenbroeck, E. and Van Hove, L. (2017), "Adoption of online grocery shopping: personal or household characteristics?", Journal of Internet Commerce, Vol. 16 No. 3, pp. 255-286.

Vargo, S.L. and Lusch, R.F. (2004), "Evolving to a new dominant logic for marketing", Journal of Marketing, Vol. 68 No. 1, pp. 1-17.

Vargo, S.L. and Lusch, R.F. (2008), "Service-dominant logic: continuing the evolution", Journal of the Academy of Marketing Science, Vol. 36 No. 1, pp. 1-10.
Expectations of unattended grocery delivery 
IJRDM

50,13

\section{6}

Yin, R.K. (2
Zeithaml, V
expect
Appendix

Yin, R.K. (2018), Case Study Research and Applications, Sage Publications, London.

Zeithaml, V.A., Berry, L.L. and Parasuraman, A. (1993), "The nature and determinants of customer expectations of service", Journal of the Academy of Marketing Science, Vol. 21, pp. 1-12. pp. 529-540.

Wollenburg, J., Hübner, A., Kuhn, H. and Trautrims, A. (2018), "From bricks-and-mortar to bricks-andclicks: logistics networks in omni-channel grocery retailing", International Journal of Physical Distribution and Logistics Management, Vol. 48, pp. 415-438.

Xu, M., Ferrand, B. and Roberts, M. (2008), "The last mile of e-commerce- unattended delivery from the consumers and eTailers' perspectives", International Journal of Electronic Marketing and Retailing, Vol. 2, pp. 20-38.

\begin{tabular}{ll}
\hline Expectation concepts and themes & Respondents \\
\hline Desired service & \\
Integrated returns & A, B \\
$\begin{array}{l}\text { Open system } \\
\text { Nondescript designs for the hardware } \\
\text { Expected standard service }\end{array}$ & A, B, D, E, H, J \\
Saving time & \\
Gaining flexibility & C, D, E, F, G, H, I, J \\
Ease of use & A, B, E, F, H, I, J \\
Predicted service & A, F \\
Sufficient level of security & \\
Personal needs & A, B, C, D, E, F, H, I, J \\
Reducing stress & \\
Limiting social interactions & B, C, E, H, I \\
Increasing spare time & B, C, E, F, H, I, J \\
Technology literacy & C, D, E, G, H, I, J \\
Situational factors & A, B, C, D, E, F, G, H, I, J \\
\hline
\end{tabular}

\section{Corresponding author}

John Olsson can be contacted at: john.olsson@plog.1th.se

For instructions on how to order reprints of this article, please visit our website:

www.emeraldgrouppublishing.com/licensing/reprints.htm

Or contact us for further details: permissions@emeraldinsight.com 